\title{
A lógica fantasmática do e-government e 0 discurso da inovação em Cabo Verde
}

Osíris Luís da Cunha Fernandes ${ }^{1}$

Fernando Gomes de Paiva Júnior 2

Nelson da Cruz Monteiro Fernandes ${ }^{3}$

Marconi Freitas da Costa ${ }^{3}$

1 Instituto de Tecnologia de Pernambuco, Recife / PE - Brasil

2 Universidade Federal de Pernambuco / Programa de Pós-Graduação em Administração, Recife / PE - Brasil

3 Universidade Federal de Pernambuco / Programa de Pós-Graduação em Gestão, Inovação e Consumo, Caruaru / PE - Brasil

O objetivo deste estudo consiste em aprofundar as reflexões sobre o e-government (e-gov) a partir de uma análise do campo discursivo da inovação no setor público em Cabo Verde, sob a ótica da Teoria do Discurso (TD) de Ernesto Laclau e Chantal Mouffe. Para tanto, por meio de estudo de caso instrumental e usando o método da retrodução proposto por Jason Glynos e David Howarth e a análise do discurso (de matriz francesa) dos sujeitos que constituíram o e-gov, buscamos desvelar a lógica fantasmática da articulação discursiva dessa prática social. Os resultados mostram, por um lado, que, embora, o e-gov seja uma entidade incompleta, vulnerável e contingente, a identidade dos agentes envolvidos em sua articulação discursiva depende de sua capacidade de reiterar os discursos de "aposta na sociedade da informação", "e-government como opção estratégica para o desenvolvimento" e "reforma do Estado e modernização administrativa" ao longo do tempo. Por outro lado, o e-gov se revelou um sistema discursivo impregnado de demandas relacionadas a um tecnicismo ocasional e à crença implícita dos agentes do setor público cabo-verdiano de que o uso das tecnologias de informação e comunicação (TIC) pelas instituições públicas gera avanços estruturadores na modernização administrativa e na transformação social.

Palavras-chave: e-government; inovação na gestão pública; teoria do discurso; análise do discurso.

\section{La lógica fantasmática del e-government y el discurso de la innovación en Cabo Verde}

El objetivo de este estudio consiste en profundizar las reflexiones sobre el e-gobierno (e-gov) a partir de un análisis del campo discursivo de la innovación en el sector público en Cabo Verde bajo la óptica de la Teoría del Discurso de Ernesto Laclau y Chantal Mouffe. Para ello, por medio de un estudio de caso instrumental y usando el método de retroducción propuesto por Glynos y Howarth y el análisis del discurso (de matriz francesa) de los sujetos que constituyeron el e-gov, buscamos desvelar la lógica fantasmática de la articulación discursiva de esa práctica social. Los resultados muestran, por un lado, que aunque el e-gov sea una entidad incompleta, vulnerable y contingente, la identidad de los agentes involucrados en su articulación discursiva depende de su capacidad de reiterar los discursos de 'apuesta en la sociedad de la información', 'e-government como opción estratégica para el desarrollo’ y 'reforma del Estado y modernización administrativa' a lo largo del tiempo. Por otro lado, el e-gov se reveló como un sistema discursivo impregnado de demandas relacionadas a un tecnicismo ocasional ya la creencia implícita de los agentes del sector público caboverdiano de que el uso de las TIC por parte de las instituciones públicas genera avances estructuradores en la modernización administrativa y en la transformación social.

Palabras clave: e-government; innovación en la gestión pública; teoría del discurso; análisis del discurso. 


\section{The phantasmatic logic of e-government and the discourse of innovation in Cape Verde}

This study aims to deepen the reflections on E-government (E-gov) from an analysis of the discursive field of innovation in the public sector in Cape Verde from the point of view of Laclau and Mouffe's Discourse Theory. An instrumental case study was conducted using the reproduction method proposed by Glynos and Howarth and discourse analysis (French matrix). The aim was to unveil the phantasmatic logic of the discursive articulation of this social practice of the subjects that constituted the E-gov. The results show that although E-gov is an incomplete, vulnerable, and contingent entity, the identity of the agents involved in its discursive articulation depends on its capacity to reiterate the discourses of 'the information society,' 'E-government as a strategic option for development,' and 'state reform and administrative modernization' over time. However, E-gov has revealed itself as a discursive system impregnated with demands related to an occasional technicality and to the implicit belief of agents of the Cape Verdean public sector that the use of ICT by public institutions generates structuring advances in administrative modernization and social transformation.

Keywords: e-government; innovation in public management; discourse theory; discourse analysis.

\section{INTRODUÇÃO}

A presença da tecnologia na organização de quase todas as práticas sociais constitui uma das características mais marcantes das sociedades contemporâneas, a ponto dos regimes de saber e fazer praticamente se confundirem entre si, sob o reinado de tal tecnologia (Rensburg, Telukdarie, \& Dhamija, no prelo). Nesse contexto, o conhecimento constitui tanto um fator-chave de entrada (input) como de saída (output) de inovação na gestão pública, além de um recurso primordial para a dinamização institucional de diversos processos de inovação, os quais tornam imperativa sua transformação em novos conhecimentos (Heeks, 2003; Klabi, Mellouli, \& Rekik, 2018).

Essas rupturas demandam a emergência de novos modelos de gestão pública e formas complexas e inovadoras de ação institucional por parte dos governos (Secchi, 2009; Castro, Ferreira, \& Costa, 2019), além da adoção de novos instrumentos e procedimentos que auxiliem os gestores públicos na resposta às transformações e exigências dessas sociedades (Palaco, Park, Kim, \& Rho, 2019). Os problemas das sociedades contemporâneas tornam inexorável o discurso das novas tecnologias de gestão, com uso de ferramentas vigentes no universo das tecnologias de informação e comunicação (TIC) (Czamanski \& Broitman, 2017). Diante disso, esses governos têm procurado formas alternativas de intervenção, por meio da formulação de políticas públicas para inovação e aceleração de criação e difusão de processos inovadores no setor público (Arundel, Bloch, \& Ferguson, 2019).

Os discursos dos governos vão no sentido de dinamizar seus organismos e serviços que geram as condições de possibilidade para o surgimento e a implementação de projetos de e-government (e-gov) orientados por uma lógica de simplificação e democratização do acesso dos cidadãos e das empresas aos serviços públicos (Twizeyimana \& Andersson, 2019). Neste estudo, sob a inspiração da concepção proposta pela Organização das Nações Unidas (ONU) e pela Sociedade Americana de Administração Pública (American Society for Public Administration [ASPA]), o conceito de e-gov se refere ao uso da World Wide Web (WWW) no provimento de informações e serviços do governo aos cidadãos (Verkijika \& DeWet, 2018).

Apesar dos avanços registrados no campo do e-gov, alguns governos têm negligenciado o fato de que o sucesso da reorganização do back-office e do front-office depende da reestruturação orgânica dos governos e da disponibilização on-line de serviços públicos - mediante políticas, estratégias e ações -, além do incentivo à maior participação dos cidadãos e à accountability (Stefanovic, Marjanovic, Delić, Culibrk, \& Lalic, 2016). A falta de diligências com esses casos tem levado ao fracasso de muitos projetos de e-gov em muitas latitudes (Heeks, 2003). 
Segundo Larsson e Gronlund (2016), muitos Estados-nação ainda não conseguem implementar projetos de e-gov que respondam, adequadamente, a determinadas demandas sociais próprias desta era. Em parte, segundo Mauro, Cinquini, e Pianezzi (no prelo), isso se deve a fatores como a maior complexidade da agenda pública e dos problemas sociais, das restrições financeiras, da dependência de decisões de instâncias governamentais superiores internacionais ou de organizações privadas, para além de práticas clientelistas na gestão do setor público, do controle das atividades de inovação por agências do governo e da centralização da gestão dos sistemas de inovação.

Comandados pelo discurso de aumento de competitividade e efetividade governativa de determinados agentes políticos e governos, os projetos de implementação das atividades de inovação no setor público em Cabo Verde também apresentam suas contradições, com tendências centralizadoras das atividades de inovação, práticas antidemocráticas e antipluralistas da gestão pública (O’Flynn, 2007). Diante disso, partindo da concepção do e-gov como fruto de uma construção discursiva (Klabi et al., 2018), propomo-nos a analisá-lo a partir do entendimento das fantasias articuladas pelos principais agentes sociais envolvidos nas disputas pela fixação de sentidos dessa prática social em Cabo Verde.

Os limites ou descaminhos do e-gov precisam ser analisados por meio da investigação dos processos de articulação discursiva que geram suas condições de possibilidade enquanto prática social (Lee-Geiller \& Lee, 2019). Para os efeitos deste estudo, e tendo em vista a coerência com os pressupostos teóricos e epistemológicos que o sustentam, adotamos uma concepção de e-gov que o reconhece como campo de discursividade. Dessa forma, deve ser estudado como uma prática social que visa A orientar determinados desenvolvimentos simbólicos, por meio da obtenção de consensos, tendo em vista as ações inovadoras na gestão pública, ou, ainda, determinada ordem e/ou o alcance de uma transformação social almejada (Canclini, 2019). Com isso em mente, elaboramos a seguinte questão norteadora do estudo:

- Quais são as fantasias articuladas pelos agentes relevantes do e-gov em Cabo Verde nas disputas pela fixação de sentidos dessa prática social?

Como política de inovação no setor público, o e-gov resulta de disputas discursivas, por meio das quais determinados grupos (particulares) procuram defender determinadas demandas (particulares), constituindo, para tal, suas representações (Arundel et al., 2019). Portanto, é com essa concepção de e-gov em mente que optamos pelos aportes teóricos da Teoria do Discurso (TD), visando a superar as lacunas que os modelos analíticos desse fenômeno baseados em seus estágios de desenvolvimento apresentam e as limitações das teorias de inovação no campo dos estudos organizacionais para o entendimento das questões políticas que o envolvem enquanto prática social discursiva.

\section{FUNDAMENTOS TEÓRICOS}

\subsection{A Teoria do Discurso de Laclau e Mouffe}

Em Hegemony and socialist strategy, Laclau e Mouffe (1985) empregam o pensamento pós-estruturalista como abordagem para análises políticas no sentido mais estrito. Essa estratégia lhes possibilitou a desconstrução de muitos conceitos clássicos do pensamento social e político, a exemplo de: ideologia; poder; ordem; emancipação; universalidade/particularidade; e sociedade/social (Kolvraa, 
2018). Podemos dizer, então, que o pós-estruturalismo se deparou com aquilo que Marchart (2007) denominou "giro político", a partir do qual se reconceituam o social, discursivamente, e a identidade do sujeito, enquanto resultado de articulações discursivas, além da defesa da impossibilidade da sociedade e de um projeto emancipatório nos moldes da modernidade (Smith, 2012).

Sob essa ótica, o e-gov deve ser entendido como fruto de articulações discursivas nunca totalmente conclusivas, uma vez que sua significação não pode ser fixada de forma definitiva (Fairclough, 2008). Isso abre caminho para lutas constantes (relacionadas às definições dessa prática) envolvendo o Núcleo Operacional da Sociedade da Informação (NOSI) como um dos agentes mais relevantes da cadeia de significação do e-gov em Cabo Verde, lutas estas relacionadas às definições de tal prática no país. A TD está inserida em uma "matriz contemporânea e pós-estruturalista, que contempla a contingência, a precariedade, a indeterminação e o paradoxo como dimensões ontológicas do social" (Mendonça \& Rodrigues, 2008, p. 26) e constitui um sofisticado arcabouço teórico para a compreensão do social, adotando o poder e o discurso como categorias centrais (Snir, 2017).

Laclau e Mouffe (1985, p. 105) definem discurso como uma "totalidade estruturada resultante da prática articulatória". Isso pressupõe a existência de um conjunto de elementos vinculados entre si em uma cadeia de equivalências e aqueles excluídos dessa mesma cadeia (Snir, 2017). Isto é, no âmbito do discurso, o significado é construído em termos de equivalência e diferença (de forma metonímica ou metafórica), sendo que em algumas situações a lógica da diferença predomina, ao passo que em outras a lógica da equivalência prevalece (Howarth, 2005). No entanto, na maioria das vezes, os significados são formulados tanto pela afirmação da diferença como pela articulação de cadeias de equivalência.

Essa concepção reforça nossa conviç̧ão em relação à capacidade explicativa da TD, relativamente ao fenômeno do e-gov, uma vez que ela nos permite conhecer suas práticas articulatórias expressas nos embates pela fixação de seus significados no contexto social cabo-verdiano. Em termos metodológicos, na aplicação da TD, concentramos nossos esforços na exploração da lógica fantasmática a fim de entendermos quais são as fantasias e como são articuladas pelos agentes relevantes do $e$-gov em Cabo Verde nas disputas pela fixação de sentidos dessa prática social.

\subsection{A lógica fantasmática}

O ser humano é sujeito do desejo, portanto, possuidor de afetividade e imaginação (Lacan, 2008). Por isso, a lógica da fantasia teoriza a conexão do sujeito simbólico com algo que não é de sua ordem (simbólica) de significação (Salter, 2016): o real (de gozo). Essa lógica nos permite analisar o enjoyment (aqui entendido como gozo) que os sujeitos procuram em suas articulações discursivas do e-gov.

A lógica da fantasia opera no sentido de possibilitar uma forma de fechamento ideológico da contingência radical das relações sociais e a naturalização das diferentes relações de dominação nas quais os sujeitos se envolvem (Howarth \& Griggs, 2012). Nessa visão, a fantasia é concebida como um cenário imaginário cuja função consiste em fornecer um tipo de suporte positivo para o preenchimento da lacuna constitutiva do sujeito (Ostermann, 2019). O mesmo é válido para a fantasia social, que compreende um cenário imaginário que preenche as lacunas da estrutura social, escondendo seu antagonismo constitutivo com a plenitude do gozo. Ou seja, constitui uma contrapartida necessária ao conceito de antagonismo (Laclau, 1990).

Como as fantasias constituem uma ilusão ideológica ou formas de falsa consciência (Glynos \& Howarth, 2007), elas auxiliam na organização, ainda que parcialmente, de nossas percepções do e-gov. Ademais, como abarcam sua contingência radical, as fantasias ajudam na estruturação de 
nosso entendimento das relações sociais no campo de discursividade da inovação do setor público em Cabo Verde. É importante destacar, todavia, que o "sucesso" de determinada fantasia nessa arena discursiva depende de sua invisibilidade, pois figuras e dispositivos fantasmáticos deixam de funcionar apropriadamente quando se tornam visíveis (Clarke, 2011).

A lógica fantasmática diz respeito à força por trás das operações de significação e permite explicar tanto a inércia na manutenção das práticas como a velocidade das mudanças que ocorrem nelas (Salter, 2016). Nas práticas sociais (ou políticas), a fantasia opera para ocultar a contingência radical das relações sociais (Glynos, 2008). E ocorre quando os agentes sociais usam uma narrativa fantasmática ou lógica que envolve alguma referência a um cenário idealizado, ou uma plenitude por vir, uma vez superado um obstáculo nomeado (a dimensão beatífica da fantasia) ou, então, uma narrativa que prevê o desastre, caso o obstáculo nomeado se mostre insuperável (o lado horrível da fantasia) (Lacan, 2008).

Nesse sentido, se a realidade política compreende uma construção simbólica, certamente ela depende da fantasia para se constituir (Ostermann, 2019). Logo, a lógica fantasmática nos permite compreender não apenas a natureza das ações inovadoras no setor público cabo-verdiano como os discursos que articulam a resistência ao $e$-gov, mas, igualmente, entender melhor a velocidade e a direção dos discursos que sustentam essas inovações.

\subsection{0 e-gov no contexto da Nova Gestão Pública}

A Nova Gestão Pública (NGP) se tornou um termo amplamente usado no campo dos estudos organizacionais e descreve uma tendência global de determinado tipo de reforma administrativa (Mauro et al., no prelo). No entanto, ficou evidente que a NGP assume diferentes significados em contextos administrativos distintos (Ashraf \& Uddin, 2016). Para efeitos deste estudo, refere-se ao movimento uniforme e global de reformas no governo. A principal característica de reformas da NGP é a mudança de orientação de input para output (O’Flynn, 2007).

É nesse contexto que surge o $e$-gov na noção de inovação ininterrupta na prestação de serviços, na participação cidadã e na governança por meio da mudança das relações internas e externas pelo uso das TIC, especialmente a internet (Lee-Geiller \& Lee, 2019). Isso exige uma transformação estrutural na lógica subjacente aos processos e procedimentos administrativos do Estado e uma redefinição das fronteiras entre esse Estado, o cidadão e outros atores da sociedade civil, a exemplo dos agentes paraestatais e as organizações não governamentais (ONGs) (Klabi et al., 2018).

Para Twizeyimana e Andersson (2019), o e-gov é um movimento de reforma orientado pela tecnologia em que a estratégia de reforma segue o potencial criado por modernas TIC. Ou seja, a centralidade do conceito de e-gov reside no uso das TIC em todas as arenas onde seja possível reconstruir a estrutura de governo, redesenhar processos, informatizar atividades operacionais e prover serviços melhores para a sociedade (Czamanski \& Broitman, 2017).

$\mathrm{O} e$-gov apresenta um caráter eminentemente relacional, pois não se restringe à implementação de novas tecnologias, mas se traduz no estreitamente das conexões entre todos os atores que se relacionam com o governo: os cidadãos, os fornecedores e outros governos (Palaco et al., 2019). Foi pensando nisso que realizamos esta empreitada em busca da compreensão do e-gov como prática discursiva, a partir da análise das fantasias articuladas pelos atores sociais envolvidos com o e-gov nas disputas discursivas pela fixação de sentidos dessa prática em Cabo Verde. 


\section{PROCEDIMENTOS MÉTODO-ANALÍTICOS}

\subsection{Caracterização e natureza da pesquisa}

A perspectiva ontológica e epistemológica desta pesquisa se insere na orientação do construcionismo social (Berger \& Luekmann, 2004). A natureza do objeto deste estudo pode ser mais bem compreendida sob os auspícios da tradição qualitativa (Godói, Bandeira-de-Mello, \& Silva, 2010). Para a análise da lógica fantasmática da articulação discursiva do e-gov, adotamos a análise de discurso (AD) de matriz francesa como procedimento analítico, uma vez que ela fornece um quadro geral para investigação social orientada por problemas. Adotamos o método da retrodução (Glynos \& Howarth, 2007), com o intuito de investigar quais fatores criaram historicamente as condições para a implementação, manutenção, aceitação do projeto do e-gov em Cabo Verde.

\subsection{Coleta dos dados}

Para efeitos deste estudo, definimos o NOSI de Cabo Verde como sujeito central da enunciação, considerando sua expressiva representatividade no campo de discursividade em estudo, representa a agência do Estado que controla as atividades de inovação no setor público, e o responsável pelo delineamento de políticas, estratégias e execução de ações relacionadas ao e-gov e à sociedade da informação em Cabo Verde. Contudo, o caso Cabo Verde é secundário e serve para ajudar na compreensão de um fenômeno mais amplo, o e-gov, em uma perspectiva discursiva.

Flick (2006) recomenda para a pesquisa qualitativa 4 tipos básicos de procedimentos de coleta de dados, a saber: a) observação; b) entrevistas; c) documentos; e d) materiais audiovisuais. Reconhecendo a pertinência desses procedimentos, utilizamos todos eles no levantamento de dados, mas sempre tendo em consideração nossos julgamentos intuitivos sobre a importância e o significado deles para este estudo.

Durante o período de coleta de dados, fizemos visitas periódicas ao NOSI, durante as quais realizamos algumas entrevistas e participamos de reuniões (como observador não participante) e eventos relacionados ao e-gov em Cabo Verde. A observação também serviu para obtermos informações que ajudaram a corrigir algumas imprecisões do momento das entrevistas. Cada nota de observação foi analisada sob a forma de nota de observação $(\mathrm{NO})$ e o número que segue as letras corresponde à sequência (NO1, NO2, NO3...) em foco.

\subsection{Análise dos dados}

Decidimos por organizar e gerir os dados/as informações fazendo uso do software NVIVO, um programa de computador para análise de dados qualitativos que, além de ser um gerenciador de base textual utilizado para todos os tipos de arquivos eletrônicos, pode ser utilizado na codificação e recuperação de códigos em documentos.

Realizamos 15 entrevistas, sendo 7 com funcionários do NOSI, 4 com cidadãos usuários de serviços do e-gov, 3 com funcionários públicos (de outras instituições que não o NOSI) e 1 com uma deputada da nação. Para efeitos de nossa pesquisa, privilegiamos a coleta de dados com o coordenador dos sistemas de informação, o gestor, coordenadores dos departamentos, técnicos do departamento de informática e multimídia e do departamento de comunicação e imagem, gestores de negócio - uma 
figura recente na estrutura orgânica do NOSI -, além de outros agentes que se revelaram importantes no campo de discursividade e que fazem parte da cadeia articulatória como cidadãos usuários finais de serviços do e-gov, funcionários públicos de outros ministérios que foram impactados por esses serviços e com lideranças políticas envolvidas com restruturação administrativa do Estado.

Nas entrevistas com esses atores, nosso objetivo foi tentar perceber/desvelar quais significados atribuem ao e-gov em suas articulações discursivas e procurar entender sua percepção a respeito da atuação do NOSI no âmbito da inovação no setor público em Cabo Verde. Perguntamos a eles a respeito de suas ações (articulações) políticas, considerando o controle das atividades de inovação no setor público pelo NOSI e as mudanças que essas articulações podem ocasionar na organização das instituições públicas e os efeitos desses serviços no cotidiano do cidadão comum.

Estamos cientes de que talvez esses sujeitos não tenham dado uma explanação completa de suas ações ou intenções, mas acreditamos que nos ofereceram insights sobre suas práticas na disputa incessante pela significação do $e$-gov.

Para preservar a identidade dos entrevistados apresentamos apenas a inicial de seus primeiros nomes e cada entrevista foi analisada sob a forma de entrevista (E), referência ( $\$$ ) e sequência das linhas em foco, extraída do NVIVO após a codificação: E1, \$1: 1-10.

Quanto às questões das entrevistas qualitativas, estas foram agrupadas em 3 tipos: a) as principais; b) as exploratórias; e c) as de acompanhamento. Realizamos uma criteriosa e consistente seleção de documentos oficiais, legislações e relatórios técnicos e oficiais. Visitamos o site das ONU sobre as redes de administração pública e a base de dados do e-gov no mundo e o E-Regulations de Cabo Verde. Durante as análises, cada documento foi analisado sob a forma de documento oficial (DO) seguido da referência $(\$)$ em foco, extraída do NVIVO após a codificação: DO1, $\$ 1$.

As legislações (LG) foram analisadas junto com a referência (\$) em foco, extraída do NVIVO após a codificação: LG1, \$1. O levantamento das legislações abarcou o período de 1975 a 2012. Os relatórios (RE) foram analisados junto com a referência ( $\$$ ) em foco, extraída do NVIVO após a codificação: RE1, \$1. Este relatório foi publicado em 2014. Na busca pela identificação das práticas discursivas fora do enquadramento dos agentes hegemônicos (e fora do espaço institucional), recorremos à imprensa escrita. Um total de 90 notícias foi utilizado na construção do corpus analítico. As notícias (N) foram analisadas junto com a referência ( $\$$ ) em foco, extraída do NVIVO após a codificação: N1AS1, \$1. Os textos jornalísticos e das mídias sociais coletados foram publicados entre 2010 e 2014.

Selecionamos 9 vídeo-reportagens publicados pelo NOSI e 19 vídeos de notícias sobre o e-gov em Cabo Verde. Durante as análises, esse material audiovisual (MA) foi analisado junto com a referência (\$) em foco, extraída do NVIVO após a codificação: MA1, \$1. O levantamento do material audiovisual abarcou o período de 2010 a 2014.

\section{RESULTADOS E DISCUSSÃO}

\subsection{Desvelando a lógica fantasmática da articulação discursiva}

A existência de um contexto político e social específico da República de Cabo Verde contribuiu para que o e-gov fosse implementado e que fossem geradas condições de possibilidade para introdução de ações inovadoras na gestão do setor público cabo-verdiano. 
Boa governança e uma adequada gestão macroeconômica, a par da abertura ao comércio e a crescente integração na economia global, bem como a adoção de políticas de desenvolvimento social eficazes, fazem parte das metas definidas pelo Banco Mundial (BM, 2019) para os países em desenvolvimento e serviram de base para uma reconhecida trajetória de desenvolvimento do país. Essas diretrizes estão nas entrelinhas da missão definida para o NOSI. Com esses propósitos de gestão, Cabo Verde foi aceito como um parceiro especial da União Europeia (UE) em novembro de 2007, e em dezembro do mesmo ano como membro da Organização Mundial do Comércio (OMC). Em janeiro de 2008, foi graduado pela ONU como "País de Rendimento Médio", sendo o segundo na África Subsaariana a alcançar essa ascensão, após Botswana, e a primeira graduação em mais de uma década na África (Madeira, 2016; Monteiro, 2011).

O NOSI se insere nesse contexto a partir de 1998 com a fundação da Unidade de Reforma da Administração Financeira do Estado (RAFE), organismo já extinto, considerado o embrião do e-gov em Cabo Verde. O projeto da RAFE era limitado ao Ministério das Finanças, que tinha iniciado o investimento na introdução de plataformas tecnológicas e novos mecanismos de gestão baseados nas TIC, desenvolvidos por jovens técnicos cabo-verdianos, com o objetivo de melhorar a gestão financeira do Estado. A experiência foi bem-sucedida e, pouco a pouco, alastrou-se para outros setores da administração pública, levando o governo a criar uma unidade transversal e abrangente para operar uma profunda reforma do Estado e uma modernização administrativa, tendo as TIC como alicerce. A instalação formal do NOSI se deu apenas em janeiro de 2004, nas dependências do prédio do Ministério das Finanças, no Plateau, centro histórico da cidade da Praia (Resolução n. 15, 2003). As atividades do NOSI abrangem toda a administração direta e indireta do Estado, incluindo os governos municipais (Núcleo Operacional da Sociedade da Informação [NOSI], 2005a).

Com o passar dos anos o coordenador de sistemas de informação tem exercido um papel-chave no estabelecimento de articulações entre o gestor e as chefias intermédias, bem como no acompanhamento e na coordenação geral dos projetos que têm como meta colocar o cidadão no foco do serviço público, participar na modernização da sociedade e no crescimento econômico, impulsionando, desse modo a sociedade do conhecimento, nomeadamente por meio da inovação e de mecanismos de governança eletrônica integrada, para facilitar o cotidiano dos cidadãos e dos agentes econômicos e elevar os padrões de competitividade e melhoria da qualidade de vida dos cabo-verdianos.

Esse contexto reforça uma ideologia acerca dessa prática social, ainda em construção, que, na perspectiva da teoria do discurso, funciona como uma fantasia buscando suprir o vazio que permeia as práticas sociais. Essa fantasia constitui uma tentativa de estabelecer um fechamento a várias questões em disputa na sociedade cabo-verdiana.

A lógica fantasmática se sustenta nas fantasias utilizadas pelo governo de Cabo Verde, tanto para sustentarem e perpetuarem práticas de fixação de sentido como para engajar os diferentes atores da sociedade em direção a novos projetos. Por meio de uma narrativa que promete plenitude e superação de obstáculos, essa lógica atua na ocultação da dimensão política e na contingência das relações sociais. Por isso, ela desempenha um papel relevante na construção das cadeias de equivalência, utilizado pelos indivíduos para forjar uma unidade em torno de um projeto de nação, oriunda de uma multiplicidade de posições (Glynos \& Howarth, 2007).

O e-gov integra o discurso de reforma do Estado e modernização administrativa, de modo que sua lógica fantasmática está vinculada aos domínios desse discurso: suas fantasias, articuladas, maioritariamente, no espaço midiático, estão relacionadas a: a) transformação de Cabo Verde em 
cyber islands; b) criação de um cluster TIC em Cabo Verde; e c) transformação de Cabo Verde em um centro internacional de negócios (Figura 1). Vamos atribuir essas categorias um cunho analítico para auxiliar as análises a trabalhar a seguir. Elas não são mutuamente excludentes, mas servem para regrar o ordenamento dos dados e simplificar a condução das análises.

\section{FIGURA 1 LÓGICA FANTASMÁTICA DO E-GOV NA REPÚBLICA DE CABO VERDE}

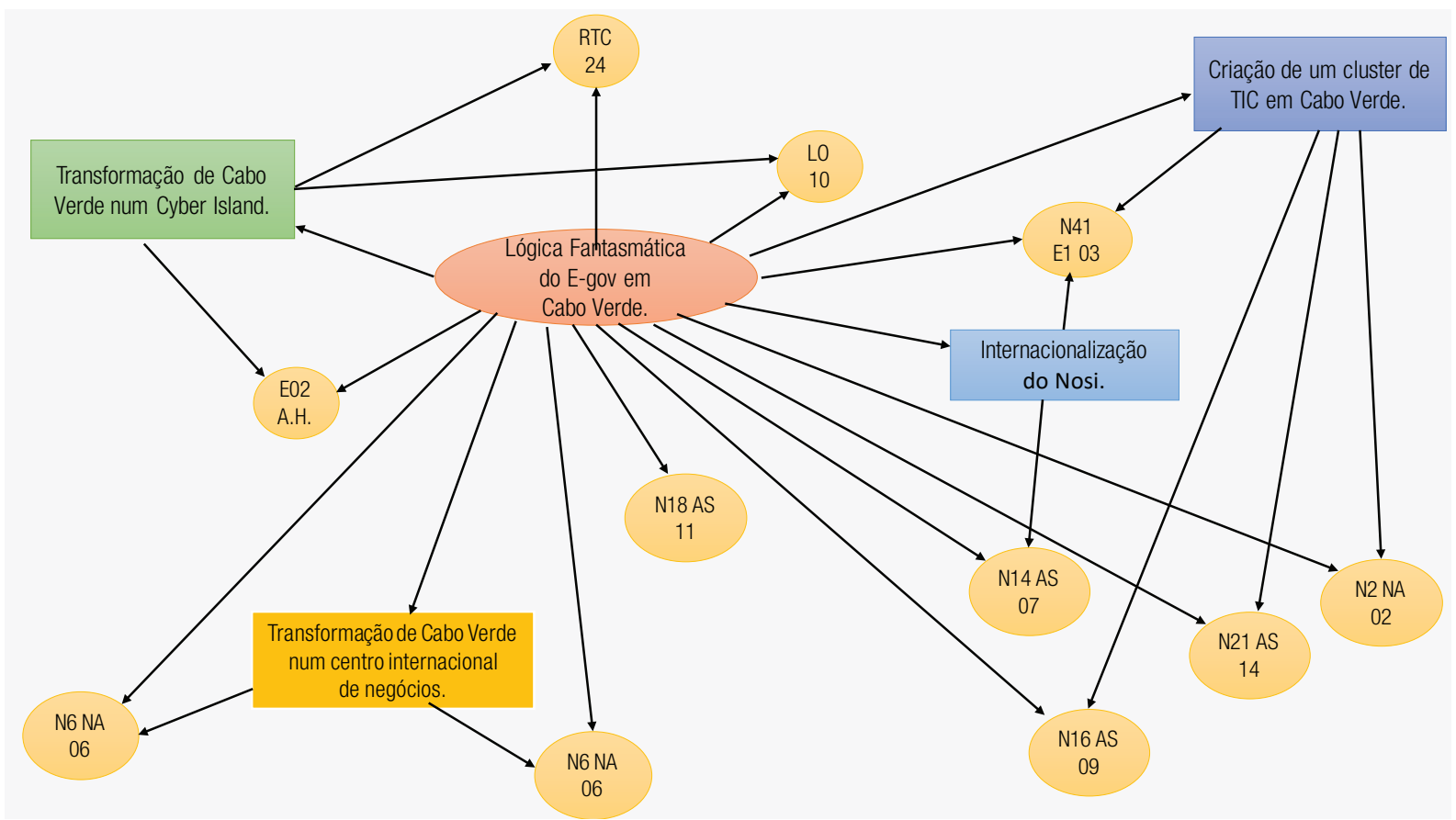

Fonte: Elaborada pelos autores.

\subsubsection{Transformação de Cabo Verde em cyber islands}

O governo cabo-verdiano utiliza a narrativa de que o controle das atividades de inovação (tecnológica) no setor público, por meio do NOSI, possibilitou a geração de condições para a implementação do e-gov com o objetivo de convencer os outros agentes sociais a aderirem ao seu discurso de reforma do Estado e modernização administrativa. Para tal, articula frequentemente em seus discursos a fantasia de transformação de Cabo Verde em cyber islands, como estratégia de dinamização do mercado das TIC em Cabo Verde e como forma de atrair grandes multinacionais das TIC, como a Huawei, que procuram o mercado africano. Nesse caso, para essas multinacionais, o país atuaria como uma espécie de porta de entrada para o continente africano, como mostram os recortes do corpus analítico deste estudo:

Uma vez que o e-gov, para nós, é um produto, porque não transformar Cabo Verde em cyber islands para que as grandes corporações, como a Microsoft, Cisco, Oracle, vejam Cabo Verde como um ponto de desenvolvimento de seus produtos, como já foram a Índia, o México e a Irlanda? Nós temos 
grandes vantagens, como a posição geográfica, uma governação transparente, temos a capacidade humana nesse momento para desenvolver produtos e, principalmente, nós somos poucos, o que é também uma vantagem. É mais fácil para as grandes corporações fazerem deployment de seus produtos num mercado como o nosso (E02, \$2: 188-198).

Percebemos que esses atores sociais criam o cenário idealizado do cyber islands para montar o discurso fantasmagórico. Essa construção simbólica auxilia na criação dos consensos, oculta os dissensos e a contingência radical das relações sociais (Glynos, 2008). Ou seja, a fantasia do cyber islands deverá justificar o empreendimento que tem o potencial de realizar a plenitude das demandas da gestão pública e que deve gerar as condições de possibilidade para o desenvolvimento do país.

Com esse discurso, consegue-se mostrar a necessidade de superar o modelo burocrático weberiano no contexto institucional contemporâneo e o descolamento dos pressupostos fundamentais para o desenvolvimento do país, agora pautada no desenvolvimento das tecnologias de informação (Twizeyimana \& Andersson, 2019). Nesses termos, alinham-se com os discursos da administração pública gerencial (APG) e do governo empreendedor (GE) ou da governança pública (GP), que incorporam as narrativas de ações inovadoras na administração pública que visam ao alcance da produtividade, orientação para o serviço, eficiência na prestação de serviços, mercantilização, accountability e descentralização (Secchi, 2009).

Os limites impostos pela articulação dos agentes relevantes e seus interesses nos diversos contextos são condições encobertas para a materialização das fantasias (Salter, 2016). Por exemplo, em relação à fantasia da transformação de Cabo Verde em cyber islands, alguns agentes da cadeia articulatória antagônica ao discurso do e-gov argumentam:

[...] o Governo continua a mostrar desnorte na matéria vital das telecomunicações no que respeita, designadamente, à diversidade e à qualidade dos serviços prestados, aos custos envolvidos e às potenciais implicações do setor na economia nacional, um ano depois da apresentação da nova Lei de Comunicações ao Parlamento. E, tudo isso, diz Humberto Cardoso, "não obstante as frases atiradas ao ar, como Praia digital, proclamações visionárias de cyber islands e obsessões como o NOSI” (N70LO10, \$1-3: 169-174).

Temos, também, que investir mais na mobilidade, com soluções para PDAs, smartphones etc. A ideia éfazer o e-gov mobile, o que vai ser um grande passo, pois o cidadão vai poder utilizar serviços públicos onde quer que esteja. Mas, para chegarmos em cyber islands, temos muito que fazer. Neste momento dependemos de questões de estratégia e não técnicas (E02, \$2: 202-206).

A despeito dos antagonismos, ou seja, da existência dos atores sociais envolvidos nas disputas discursivas relacionadas ao e-gov e na fixação de sentidos dessa prática em Cabo verde, o significado do e-gov tem sido construído em termos de equivalência, em vez da diferença (Howarth, 2005). A fantasia de transformação de Cabo Verde em cyber islands representa, também, uma construção simbólica para significar o e-gov como a prática social que possibilitará a transformação da lógica de prestação de serviços públicos e o uso das novas TIC para alavancar a competitividade da economia cabo-verdiana.

A força dessa fantasia tem suas raízes em antigas análises, como as de Osborne e Gaebler (1992), quando criam o termo "governo empreendedor", como sendo um estilo pragmático de gestão pública e 
demonstrando os benefícios das reformas na gestão pública, por meio da combinação da inovação com a utilização de ferramentas das TIC. Esses estudiosos enfatizaram a necessidade do desenvolvimento de uma governança e de arranjos organizacionais mais eficazes, que facilitassem o aumento da capacidade de oferta de serviços prestados pelo Estado. Mais do que a simples introdução de versões eletrônicas dos serviços já existentes, essas ações demandam a configuração de arquiteturas de informação com possibilidades de ser exploradas por intermédio e no interior de novos canais de serviços.

\subsubsection{A criação de cluster TIC em Cabo Verde}

Pela fantasia da criação de um cluster TIC, em Cabo Verde, os agentes relevantes na articulação discursiva do e-gov procuram atrelar a essa prática uma gama de possibilidades e novos desafios, em termos econômicos e do paradigma da governança, em busca da hegemonização de seus discursos (Laclau, 1990). Nesse sentido, pode-se afirmar que o discurso de reforma do Estado e modernização administrativa, por meio do e-gov, compreende um imaginário idealizado de negócios rentáveis com as TIC (Czamanski \& Broitman, 2017), a partir de um parque tecnológico instalado na cidade da Praia, em Cabo Verde, capaz de trazer contrapartidas financeiras, de acordo com parâmetros internacionais.

O centro de dados cabo-verdiano vai albergar uma plataforma de inteligência de serviços. Conforme o gestor do NOSI, o acordo envolve, além de uma relação de parceria mutuamente vantajosa, uma dimensão de negócio rentável, cujas contrapartidas, para a instituição cabo-verdiana, estão de acordo com os parâmetros internacionais nesse tipo de transações:

A assinatura do acordo foi um momento histórico porque marca o início da operacionalização e rentabilização do Centro de Dados, um dos pilares do Centro Tecnológico. Assim, "estão assentes nestes pilares a materialização da estratégia do Governo Cabo-Verdiano de criar, em Cabo Verde, um cluster das tecnologias da informação e da comunicação" (N16AS 09, \$1-2, 28-38).

A lógica discursiva do cluster deve permitir essa série de experimentações e práticas como negócios rentáveis e parcerias estratégicas a partir das ilhas de Cabo Verde, que acabam criando um movimento benigno para a criação dos consensos necessários para tornar possível esse empreendimento. Nos termos de Wittgenstein (2005), trata-se de um contexto que cria uma lógica discursiva que possibilita evidenciar e justificar suas práticas. Ou seja, a criação do cluster abre as portas para a incorporação dos discursos da nova economia institucional e do gerencialismo em reformas no setor público (Mauro et al., no prelo).

Assim, a geração dessa lógica discursiva da criação do cluster TIC em Cabo Verde é suficiente para captar a natureza das articulações presentes na relação entre o NOSI e os diversos protagonistas que regulamentam e executam as ações em torno do e-gov em Cabo Verde. A partir desse posicionamento, pode-se caracterizar as articulações discursivas do e-gov e colocar em evidência os esforços para sua viabilização ou anulação:

O cluster tem princípio, mas não tem fim, é um processo. Lá porque começamos agora a falar em cluster, isso não quer dizer que estamos, só agora, a começar a sua construção. O cluster tem vindo a ser construído de alguns anos a esta parte. Hoje, se calhar, temos uma preocupação mais institucionalizada para arrumar melhor as peças do puzzle: as empresas, as academias, mas ainda 
temos de trabalhar muito, melhorar muito. Portanto, penso que, neste momento, estamos a dar forma ao cluster e acho que temos um potencial de capacidade nacional que, se for bem trabalhado, com humildade, mas muita determinação, podemos ir longe. Podemos fazer das tecnologias de informação e comunicação um setor que pode contribuir para a riqueza nacional (N21AS14, \$3: 90-97).

Esse recorte testemunha que a lógica fantasmática do e-gov se sustenta, nos termos de Glynos e Howarth (2007), em um contexto idealizado de processos tecnológicos no âmbito da reforma do Estado e da modernização administrativa, que pode contribuir para a construção de uma economia mais competitiva, livre de burocracia, baseada no uso intensivo das TIC. Essa lógica também articula a questão da internacionalização do cluster que constitui a demanda mais frequentemente articulada pelo NOSI e está vinculada às fantasias de criação desse projeto e de transformação do país num centro internacional de negócios.

\subsubsection{Centro internacional de negócios}

O ideal da criação de um cluster de TIC em Cabo Verde está associado à ideia de transformação de Cabo Verde em um centro internacional de negócios. Para tanto, o governo criou um comitê de supervisão que inclui representantes da Agência de Desenvolvimento Empresarial e Inovação (ADEI), da Associação dos Jovens Empresários (AJEC), da Câmara Municipal da Cidade da Praia (CMP), das Câmaras de Comércio de Sotavento e Barlavento (CCS/B) e do Banco de Cabo Verde (BCV), com o objetivo de fiscalizar e assegurar a implementação do parque tecnológico cabo-verdiano, projeto idealizado para transformar o arquipélago no mencionado centro internacional de negócios:

Recentemente, em declarações à agência Lusa, o coordenador do "Master Plan" do parque e o gestor do Núcleo Operacional da Sociedade de Informação (NOSI), Jorge Lopes, indicou que o espaço, na prática, é um "complexo para fomentar o crescimento econômico, empresarial e de pesquisa científica e tecnológica". O objetivo é dotar Cabo Verde com um espaço de referência mundial no quadro das TIC, num centro internacional de prestação de serviços, para potenciar o desenvolvimento, a visibilidade e comercialização de serviços de e-gov, e-educação e financeiros, fomentar um clima de inovação e empreendedorismo tecnológico e concretizar parcerias com atores internacionais, de referência, no setor. O espaço contará com várias valências, entre elas uma sala multiusos, um centro de congressos, espaços para a incubação de empresas, salas para formação e qualificação e serviços comuns, como os de restauração, hotelaria e áreas de lazer e de desporto, além dos escritórios (N49EI05, §2: 149-161).

A fantasia de "internacionalização do NOSI" impulsionou diversos agentes sociais a aderirem ao discurso do e-gov, articulados especialmente pelo NOSI. Isso ocorre, essencialmente, devido à experiência dessa instituição no campo da inovação tecnológica, no setor público, com projetos e tecnologias no âmbito do e-gov, em vários países africanos, o que a faz ser vista como um agente com capacidade para abrir as portas do mercado internacional a pequenas empresas cabo-verdianas do segmento das TIC. Assim, a fantasia da internacionalização do NOSI teve forte influência no engajamento dos agentes sociais, no sentido da perpetuação do discurso da reforma do Estado e da modernização administrativa (Ashraf \& Uddin, 2016): 
O parque tecnológico será o instrumento de internacionalização do NOSI. A ideia aqui é: já que Cabo Verde domina algumas tecnologias, já conseguiu ter alguma exposição nesse sentido, pegar no tema que tem mais projeção internacional, o e-gov, arranjar um espaço físico que podemos identificar com esse tema e criar todo um ecossistema para levarmos isso para fora. Com o setor privado daqui a complementar produtos de e-gov, de Cabo Verde, vamos criar centros de certificação e de investigação e vamos começar a melhorar esse negócio de governação, de governar melhor. Vamos usar isto para exportar. Portanto, o parque tecnológico é isto, pegar no tema do e-gov e fazer com que Cabo Verde consiga exportar serviços (E1, 401-410).

A fantasia da internacionalização do NOSI impulsionou os agentes em torno do discurso do e-gov que vislumbraram na construção do novo data center e do parque tecnológico, na cidade da Praia, futuras possibilidades de negócios com produtos e serviços de governança baseados nas TIC. Nossa análise mostra que, em Cabo Verde, o e-gov é uma prática social recente cujas equivalências, diferenças e fantasias articuladas nas disputas por sua significação/constituição revelam uma tentativa de hegemonização da ideia de que a introdução e o uso das TIC nas instituições públicas permite que estas se transformem de conglomerados autocentrados em aparatos administrativos tecnologizados voltados ao cidadão. A significação do $e$-gov por seus agentes relevantes, essencialmente, como informação eletrônica e governança eletrônica demonstra preocupações deles na associação dessa prática com a racionalização e a transformação, por meio do uso das TIC, das estruturas de prestação de serviços públicos em detrimento de inovações que melhorem substancialmente a qualidade dos serviços e os processos de governança (Lee-Geiller \& Lee, 2019).

No cerne dos processos de difusão de inovação no setor público por meio do e-gov se encontra a troca de informações sobre inovação e de experiências entre as instituições públicas em rede (Palaco et al., 2019). Nesse processo complexo e não linear de comunicação e aprendizagem, essas instituições diminuem as incertezas acerca de determinadas inovações. No entanto, os resultados do estudo nos permitem afirmar que as diferenças relativamente aos discursos do $e$-gov e os significados atribuídos a essa prática justificam as dificuldades de integração entre os back-offices das diferentes instituições que compõem o setor público cabo-verdiano e contribuem para o aumento das incertezas em relação às inovações produzidas/inseridas pelo NOSI nesse setor após a implementação do $e$-gov.

Para Klabi et al. (2018), a não integração entre os diferentes back-offices não permite o compartilhamento de informações sobre as inovações entre as instituições públicas cabo-verdianas e, por isso, torna-se mais difícil a formação de uma cadeia de equivalências em torno de discursos e significados do e-gov distintos dos que têm sido articulados pelos agentes sociais, bem como em torno do papel relevante dessa prática para o desenvolvimento de ações inovadoras e atividades empreendedoras no setor público.

A significação do e-gov como informação eletrônica e governança eletrônica leva a comunicação e a aprendizagem entre essas instituições públicas a não serem entendidas como processos interativos por meio das quais elas expressam, testam e re-enquadram seus discursos sobre o e-gov (Czamanski \& Broitman, 2017). Isso ocorre porque nos discursos do $e$-gov articulados, os agentes relevantes procuram, nos termos de Laclau (2006), a hegemonização dos interesses do governo na reforma do Estado e na modernização administrativa a partir de uma configuração eletrônica dos serviços públicos.

O foco recai sobre os aspectos tecnológicos e a questão da política é tratada como dimensão de segunda ordem, uma vez que impõem desafios para o planejamento de ações inovadoras no setor 
público e para a formulação de políticas públicas que abranjam o desenvolvimento e a implementação de projetos no âmbito do e-gov e para a gestão dos sistemas de inovação, especialmente em um contexto como o da República de Cabo Verde:

O Governo vem apostando na governação eletrônica. Essa aposta constitui um imperativo para melhorar a eficácia do Estado, da administração pública, tanto a nivel central como a nível local, reforçando, assim, o Estado de Direito Democrático, uma vez que as tecnologias de informação ajudam a promover a transparência, a "accountability" e a democracia (DO3, §13).

A Governação Electrónica é um dos pilares de desenvolvimento da Sociedade da Informação em Cabo Verde, conforme estabelecido no Programa Estratégico da Sociedade da Informação (PESI) (DO3, \$6).

Essas evidências mostram que estamos tratando de um cenário em que o controle das atividades de inovação no setor público está sob o comando de uma única agência do governo, no qual os gestores públicos enfrentem dificuldades para promover a transição de uma cultura institucional, com traços de patrimonialismo e burocratismo para outra, efetivamente democrática e eficiente, que define padrões claros de accountability.

Não obstante, por um lado, a existência de uma tendência - antidemocrática e antipluralista crescente de controle das atividades de inovação e de centralização da gestão dos sistemas de inovação e, por outro lado, o fato de nenhum dos modelos analíticos vigentes conseguir ser abrangente o suficiente, a ponto de constituir um quadro teórico-analítico de referência para o avanço dos estudos sobre o $e$-gov, as expectativas crescentes de que as TIC contribuem para a modernização administrativa reacenderam o debate referente ao e-gov no campo da inovação no setor público e da gestão pública em si.

\section{CONSIDERAÇÕES FINAIS}

A proposta desta pesquisa surgiu da oportunidade de analisarmos a lógica fantasmática a partir da restituição e problematização do seguinte fato empírico: o e-gov em Cabo Verde. Para tanto, adotamos o método da retrodução de Glynos e Howarth (2007), com o intuito de rejeitamos a concepção do e-gov como uma totalidade fundante de seus processos parciais e o concebemos como prática social resultante de uma construção discursiva, sempre contingente. A problemática do estudo, que emerge dessa discussão, pode ser expressa da seguinte maneira:

- Quais são as fantasias articuladas pelos agentes relevantes do e-gov em Cabo Verde nas disputas pela fixação de sentidos dessa prática social?

Constatamos que, em Cabo Verde, o e-gov é um sistema discursivo impregnado de demandas relacionadas a um tecnicismo ocasional por força de uma crença implícita do governo em uma progressão na modernização administrativa e transformação social, a partir de inovações tecnológicas baseadas nas TIC. Essas demandas refletem a forma como as TIC são vistas e absorvidas pelas instituições públicas e revelam, também, a subordinação de servidores, métodos de trabalho e habilidades dessas instituições ao NOSI e ao governo, por meio de tais tecnologias. 
Assim, como forma de destacarmos aspectos conclusivos e responder ao questionamento central do estudo, podemos afirmar que a lógica fantasmática do e-gov (lógica que diz respeito à força por trás das operações de significação do e-gov) está vinculada, essencialmente, ao discurso de reforma do Estado e modernização administrativa. As fantasias de "transformação de Cabo Verde em cyber islands", de "criação de um cluster TIC em Cabo Verde", de "transformação de Cabo Verde em um centro internacional de negócios" são articuladas pelo governo e pelo próprio NOSI, agentes relevantes do e-gov, particularmente no espaço midiático, e visam ao engajamento dos outros agentes sociais em torno dos projetos de inovação no setor público, no âmbito do $e$-gov.

A fantasia de transformação de Cabo Verde em cyber islands compreende a promessa da criação do parque tecnológico na cidade da Praia e sua metamorfose em uma espécie de Vale do Silício caboverdiano, projeto cuja envergadura poderá gerar oportunidades de negócios com as TIC, inclusive para grandes players internacionais desse segmento, a exemplo da Huawei, que veem Cabo Verde como uma porta de entrada para o mercado das TIC que mais cresce na atualidade - o africano.

Entretanto, os limites impostos pela articulação dos agentes relevantes da cadeia contrahegemônica do e-gov e seus interesses nos vários contextos revelam condições encobertas à materialização das fantasias. Por exemplo, o MPD, o maior partido político de oposição, atualmente, considera que a fantasia da "transformação de Cabo Verde em cyber islands" representa nada mais do que outra estratégia para a transformação da lógica de prestação de serviços públicos e beneficiar, ainda mais, o NOSI no campo da inovação no setor público.

A "fantasia da criação de um cluster TIC em Cabo Verde" engaja mais as empresas privadas da área em torno do discurso da reforma do Estado e modernização administrativa articulado pelo governo, que compreende um ambiente idealizado com um variado leque de possibilidades de negócios dessas empresas com instituições públicas.

Dessa forma, a lógica fantasmática do e-gov, em Cabo Verde, sustenta-se em um cenário idealizado de processos tecnológicos, no âmbito da reforma do Estado e da modernização administrativa, que podem contribuir para a geração de negócios no setor das TIC e, consequentemente, o uso dessas TIC para a melhoria do índice de competitividade do país. Daí a vinculação da fantasia de criação de um cluster de TIC em Cabo Verde à fantasia de transformação de Cabo Verde em um centro internacional de negócios e à internacionalização do NOSI.

A experiência do NOSI com projetos de inovação tecnológica, no âmbito do e-gov, em Cabo Verde e em alguns outros países africanos (Moçambique, Guiné-Bissau, Guiné Equatorial) faz com que a fantasia de sua internacionalização impulsione os agentes sociais a aderirem aos seus discursos/ projetos e aos do governo. Portanto, os resultados deste estudo apontam que o processo de adoção/ implementação das TIC em processos de inovação no setor público depende de articulações políticas e, ao mesmo tempo, de contingências sociais e técnicas como, por exemplo, os tipos de sistemas introduzidos, quem os controlará e o tipo de infraestrutura dedicada ao seu apoio.

Dessa forma, uma implicação importante dos resultados deste estudo consiste na necessidade de entendimento pelos agentes relevantes do e-gov de que o status de indivíduo em relação aos sistemas tecnológicos é superior ou, pelo menos, tão importante quanto os procedimentos de trabalho com suporte das TIC na gestão pública. Outrossim, na avaliação e no aperfeiçoamento dos programas de inovação, no âmbito do e-gov, é importante que os agentes relevantes tenham em mente que seus discursos e suas práticas políticas se refletem diretamente nas práticas de gestão e de inovação no setor público. 
RAP | A lógica fantasmática do e-government e o discurso da inovação em Cabo Verde

Finalizando, problematizamos a prática social estudada a partir da lógica fantasmática, que aborda as ideologias presentes nas articulações discursivas, e, alinhados à proposta metodológica da retrodução, avaliamos os discursos que constituem o e-gov, em Cabo Verde. Mas pontes de discussão podem ser trabalhadas com outros campos conceituais no que eles podem aclarar o objeto de estudo. Nessa mesma temática, pode-se discutir as lógicas sociais do e-gov, incluindo seus significados dominantes nas articulações nos espaços institucional e midiático, bem como as normas, políticas, regras e autorrepresentações que o constituem. Pode ser incorporada, também, a lógica política do e-gov abordando as práticas discursivas geradoras da cadeia de equivalências em sua significação, centrando, fundamentalmente, nos conflitos e nas contestações inerentes a essa prática.

Ao focarmos as fantasias construídas em torno do e-gov, deixamos de fora as tensões que existem entre a eficiência operacional interna das instituições públicas e qualidade dos serviços que prestam, necessitando de futuros estudos que lancem luz sobre questões relativas à redução dos custos por transação cidadão/cliente e ao aumento da velocidade do processamento das demandas por serviços, com vistas a encontrar formas de impulsionar os servidores públicos a terem uma orientação para a qualidade na prestação dos serviços. 


\section{REFERÊNCIAS}

Arundel, A., Bloch, C. \& Ferguson, B. (2019). Advancing innovation in the public sector: aligning innovation measurement with policy goals. Research Policy, 48(3), 789-798.

Ashraf, J., \&Uddin, S.(2016). New public management, cost savings and regressive effects: a case from a less developed country. Critical Perspectives on Accounting, 41, 18-33.

Banco Mundial. (2019). Cabo Verde: aspectos gerais. Recuperado de http://www.worldbank.org/pt/ country/caboverde/overview

Canclini, N. G. (2019). A culture of informality. Urban Studies, 56(3), 488-493.

Castro, J. C., Ferreira, M. O., \& Costa, M. F. (2019). Estratégias de políticas públicas para redução da informalidade no setor de confecções: aplicação do método de análise hierárquica. Future Studies Research Journal, 11(2), 176-196.

Clarke, M. (2011). Talkin' 'bout a revolution: the social, political, and fantasmatic logics of education policy. Journal of Education Policy, 27(2), 173-191.

Czamanski, D., \& Broitman, D. (2017). Information and communication technology and the spatial evolution of mature cities. Socio-Economic Planning Sciences, 58, 30-38.

Fairclough, N. (2008). Discurso e mudança social. Brasília, DF: Ed. UnB.

Flick, U. (2006). An introduction to qualitative research. London, England: SAGE.

Glynos, J. (2008). Ideological fantasy at work. Journal of Political Ideology, 13(3), 275-296.

Glynos, J., \& Howarth, D. (2007). Logics of critical explanation in social and political theory. New York, NY: Routledge.

Godói, C. K., Bandeira-de-Mello, R., \& Silva, A. B. (Orgs.). (2010). Pesquisa qualitativa em estudos organizacionais: paradigmas, estratégias e métodos (2a ed.). São Paulo, SP: Saraiva.

Heeks, R. (2003). E-government in Africa: promise and practice. Information Polity, 7(2-3), 97-114.

Howarth, D. (2005). Applying discourse theory: the method of articulation. In D. Howarth, \& J. Torfing (Eds.), Discourse theory in European politics: identity, policy and governance (pp. $\mathrm{x}-\mathrm{y})$. New York, NY: Palgrave Macmilan.

Howarth, D., \& Griggs, S. (2012). Poststructuralist policy analysis: discourse, hegemony, and critical explanation. In F. Fisher, \& H Gottweis. The argumentative turn revisited: public policy as communicative practice (pp. x-y). Durham, England: Duke University Press.

Klabi, H., Mellouli, S. \& Rekik, M. (2018). A reputation based electronic government procurement model. Government Information Quarterly, 35(4), 43-53.

Kolvraa, C. (2018). The discourse theory of Ernesto Laclau. In R. Wodak, \& B. Forchtner (Eds.), The Routledge handbook of language and politics (pp. x-y). New York, NY: Routledge.

Lacan, J. (2008). A lógica do fantasma. Recife, PE: Centro de Estudos Freudianos do Recife.

Laclau, E. (1990). New reflections on the revolution of our time. London, England: Verso.

Laclau, E. (2006). La razón populista. México, DF: FCE, 2006.

Laclau, E., \& Mouffe, C. (1985). Hegemony and socialist strategy: towards a radical democratic politics. London, England: Verso.

Larsson, H., \& Gronlund, A. (2016). Sustainable eGovernance? Practices, problems and beliefs about the future in Swedish eGov practice. Government Information Quarterly, 33(1), 105-114.

Lee-Geiller, S., \& Lee, T. (2019). Using government websites to enhance democratic e-governance: a conceptual model for evaluation. Government Information Quarterly, 36(2), 208-225.

Madeira, J. P. (2016). Cabo Verde: de um "Estado inviável" ao pragmatismo na política externa. Revista de Relaciones Internacionales, Estrategia y Seguridad, 11(1), 85-101.

Marchart, O. (2007). Post-foundational political thought: political difference in Nancy, Lefort, Badiou and Laclau. Edinburgh, Scotland: Edinburgh University Press.

Mauro, S. G., Cinquini, L., \& Pianezzi, D. (no prelo). New Public Management between reality and 
illusion: analysing the validity of performance-based budgeting. The British Accounting Review.

Mendonça, D., \& Rodrigues, L. P. (2008). Pósestruturalismo e teoria do discurso: em torno de Ernesto Laclau. Porto Alegre, RS: Ed. PUCRS.

Monteiro, M. I. G. (2011). Parceria especial Cabo Verde/União Europeia-UE: uma mudança de paradigma nas relações entre Cabo Verde e UE? (Dissertação de Mestrado). Lisboa, Portugal: Universidade Técnica de Lisboa.

Núcleo Operacional da Sociedade da Informação. (2005a). Plano de Acção para a Governação Electrónica: uma governação mais próxima dos cidadãos. Praia, Cabo Verde: Alfa Comunicações.

Núcleo Operacional da Sociedade da Informação. (2005b). Programa Estratégico para a Sociedade de Informação: novas oportunidades de desenvolvimento. Praia, Cabo Verde: Book RJ.

O'Flynn, J. (2007). From new public management to public value: paradigmatic change and managerial implications. Australian Journal of Public Administration, 66(3), 353-366.

Osborne, D., \& Gaebler, T. (1992). Reinventing government: how the entrepreneurial spirit is transforming the public sector. Reading, MA: Addison-Wesley.

Ostermann, F. (2019). Applying discourse theory and interpretive policy analysis on foreign policy: the case of the French engagement in the Libyan War. SAGE Research Methods Cases. Recuperado de https://dx.doi.org/10.4135/9781526478016

Palaco, I., Park, M. J., Kim, S. K., \& Rho, J. J. (2019). Public-private partnerships for e-government in developing countries: an early stage assessment framework. Evaluation and Program Planning, 72, 205-218.

Rensburg, N. J. V., Telukdarie, A., \& Dhamija, P. (in press). Society 4.0 applied in Africa: advancing the social impact of technology. Technology in Society.

Resolução n. 15, de 7 de julho de 2003. (2003). O enquadramento institucional da actividade do Governo no domínio da sociedade de informação e do governo electrónico. Praia, Cabo Verde.

Salter, L. (2016). Populism as a fantasmatic rupture in the post-political order: integrating Laclau with Glynos and Stavrakakis. Kotuitui: New Zealand Journal of Social Sciences Online, 11, 116-132.

Secchi, L. (2009). Modelos organizacionais e reformas da administração pública. Revista de Administração Pública, 43(2), 347-369.

Smith, A. M. (2012). Laclau and Mouffe: the radical democratic imaginary. London, England: Routledge.

Snir, I. (2017). Education and articulation: Laclau and Mouffe's radical democracy in school. Ethics and Education, 12(2), 351-363.

Stefanovic, D., Marjanovic, U., Delić, M., Culibrk, D., \& Lalic, B. (2016). Assessing the success of e-government systems: an employee perspective. Information \& Management, 53(6), 717-726.

Twizeyimana, J. D., \& Andersson, A. (2019). The public value of e-government: a literature review. Government Information Quarterly, 36(2), 167-178.

Verkijika, S. F., \& DeWet, L. (2018). A usability assessment of e-government websites in SubSaharan Africa. International Journal of Information Management, 39, 20-29.

Wittgenstein, L. (2005). Investigaciones filosóficas. São Paulo, SP: Vozes. 


\section{Osíris Luís da Cunha Fernandes}

https://orcid.org/0000-0003-4158-6995

Doutor em Administração pela Universidade Federal de Pernambuco (UFPE); Diretor de Marketing e Operações do Instituto de Tecnologia de Pernambuco (ITEP). E-mail: osiriscunha@gmail.com

\section{Fernando Gomes de Paiva Júnior}

https://orcid.org/0000-0001-5715-3882

Doutor em Administração pela Universidade Federal de Minas Gerais (UFMG); Professor do Programa de Pós-Graduação em Administração da Universidade Federal de Pernambuco (PROPAD/UFPE); Coordenador do Grupo de Pesquisa Lócus de Investigação em Economia Criativa. E-mail: fernando.paivajr@pq.cnpq.br

\section{Nelson da Cruz Monteiro Fernandes}

iD

https://orcid.org/0000-0002-1662-9300

Doutor em Administração pela Universidade Federal de Pernambuco (Propad/UFPE); Ponto Focal da UFPE no Programa de Pós-Graduação em Propriedade Intelectual e Transferência de Tecnologia para a Inovação (PROFNIT/UFPE) e do Programa de Pós-Graduação em Gestão, Inovação e Consumo da Universidade Federal de Pernambuco (PPGIC/UFPE), Campus Caruaru.E-mail: cruzfernandes55@gmail.com

\section{Marconi Freitas da Costa}

https://orcid.org/0000-0001-9888-8359

Doutor em Administração pela Faculdade de Economia, Administração e Contabilidade da Universidade de São Paulo (FEA/USP); Vice Coordenador do Programa de Pós-Graduação em Gestão, Inovação e Consumo da Universidade Federal de Pernambuco (PPGIC/UFPE), Campus Caruaru; Professor Permanente do Programa de Pós-Graduação em Administração da Universidade Federal de Pernambuco (PROPAD/UFPE), Campus Recife. E-mail: marconi.fcosta@ufpe.br 